\title{
NEGOCIOS E INFLUENCIAS INFORMALES. LA RED DE PODER EN EL GOBIERNO DE BERNARDO O'HIGGINS, 1817-1823
}

\author{
BUSINESS AND INFORMAL INFLUENCES. \\ THE NETWORK OF POWER IN THE GOVERNMENT \\ OF BERNARDO O'HIGGINS, 1817-1823
}

\author{
Francisco Betancourt Castillo*
}

\begin{abstract}
Mediante el análisis de un caso en particular, este breve estudio busca identificar las características de una red de poder, justo en momentos de definición de un proceso político de profundos cambios en Chile, entre el fin del antiguo régimen y comienzos del período republicano. Al mismo tiempo, en este artículo mostraremos las diferentes aristas que surgen del cuestionamiento de la noción de "red social", especialmente si consideramos que los procesos históricos donde surgen dichas redes están condicionados por la "informalidad" institucional. Demostraremos que esta segunda noción es determinante para considerar la existencia de una red, pues lo informal traspasaba de forma tenue los límites de la legalidad vigente, permitiéndonos también reflexionar acerca de un amplio campo en la Historia, relacionado al tema de la corrupción. El caso que estudiamos es el de un grupo de comerciantes que logra tener la mayor presencia social y económica en el país durante el gobierno del Director Supremo Bernardo O'Higgins (1817-1823).
\end{abstract}

Palabras claves: Comerciantes, influencias, corrupción, redes sociales, Independencia de Chile.

Through the analysis of a particular case, this brief study seeks to identify the characteristics of a network of power, right at a time of definition of a political process of profound changes in Chile, between the end of the old regime and the beginning of the republican period. At the same time, in this article we will show the different aspects that arise from the questioning of the notion of "social network", especially if we consider that the historical processes where these networks arise are conditioned by the institutional informality. We will demonstrate that this second notion is determinant to consider the existence of a network, because the informal passed in a tenuous way the limits of the current legality, allowing us to also reflect on a wide field in History, related to the topic of corruption. The case we study is that of a group of merchants that manages to have the greatest social and economic presence in the country, during the government of the Supreme Director Bernardo O'Higgins (1817-1823).

Key words: Merchants, influences, corruption, social networks, Independence of Chile.

\section{Introducción ${ }^{1}$ \\ La reactivación de los negocios tras Chacabuco}

En los estudios concernientes a la independencia chilena aparece poco la dimensión social de la economía. Especialmente si pensamos en el ambiente en el que los negocios se desarrollaron, en una verdadera guerra civil que dividió a la sociedad, y en el cómo lo vivieron sus protagonistas. Varios testimonios acreditan que tras la batalla de Chacabuco se produjeron saqueos en varias ciudades. En estos hubo sustracción de dineros, robos en tiendas y almacenes de un variopinto tipo de mercaderías, lo que perjudicó a negociantes de diverso origen y adscripción política. Se sacaron papeles privados y documentación oficial, y se quemaron archivos públicos (AGI, Chile 544, pieza 3era, s.f.). Cajas reales y tiendas del estanco también sufrieron violencia. Los establecimientos que se libraron de esta fueron intervenidos por las nuevas autoridades, quedando deudas públicas impagas y sus acreedores desprovistos, durante años, de la posibilidad de reclamar por sus patrimonios.

Al proceso de cambios se agregaba que la mayoría de los comerciantes, tanto modestos como acaudalados, se vieron comprometidos por su apoyo al gobernador español Marcó del Pont. Más allá de la sinceridad de estos compromisos, es claro que las nuevas autoridades no vieron a muchos amigablemente. Sumados a los enemigos realistas estuvieron aquellos sospechosos de una trayectoria política indefinida, falta de apoyo al bando "patriota" o por su origen ibérico. Varios no pudieron seguir

\footnotetext{
* Universidad Bernardo O’Higgins, Santiago, Chile. Correo electrónico: efejotabetancourt@gmail.com
} 
ejerciendo su ocupación, quedando una especie de "vacío" en el mundo de los negocios, que como es lógico anunciaba grandes perspectivas y oportunidades a eventuales recién llegados.

Había espacio para los negocios en tiendas que abastecían el consumo urbano, o para aquellos que podrían dedicarse al comercio exterior, ambos ámbitos otrora ocupados por comerciantes desplazados por la guerra. El nuevo gobierno se hizo cargo de los bienes dejados por los mercaderes "fugados". El Director Supremo, en abril de 1817, señalaba que se habían secuestrado y tasado los bienes de 21 comerciantes, siendo vendidos sus bienes a particulares (Academia Chilena de la Historia 1968: 154). Las circunstancias habían demostrado además que, pese a la guerra, el comercio con Perú -el principal mercado externo- nunca se cerró del todo, ni antes ni después (Guerrero 2002; Ortega 2018: 39-59), por lo que partir de noviembre de 1819 se permitió reiniciar el tráfico marítimo con las costas peruanas desde Valparaíso (Soto 1998: 41) ${ }^{2}$.

Este comercio estuvo bajo el control del gobierno, por lo que negociantes lejanos a los nuevos gobernantes quedarían relegados, siendo favorecidos otros que sí eran cercanos. El comercio con Perú quedaba así asegurado para un grupo reducido de comerciantes radicados en Chile ${ }^{3}$. Competirían en "igualdad" de condiciones con los extranjeros en otros territorios abiertos: Europa, Norteamérica, y puertos asiáticos como Calcuta (Garreaud 1981: 89). Pero los "ingleses y Americanos del Norte", según el comerciante José Trucios, poseían mayor capital, contactos, dominio de idiomas y conocimientos para esta nueva etapa. El Tribunal del Consulado manifestó su oposición al nuevo gobierno por motivaciones económicas, no por cuestiones políticas ${ }^{4}$, como al traslado de la aduana general desde Santiago a Valparaíso, medida enfocada a convertir al puerto en un mercado de paso (Salazar 2009: 97-129) ${ }^{5}$.

El primer impulso vino por la situación militar. El ejército de los Andes debía ser atendido con víveres en Santiago. También estaba el requerimiento de proveedores permanentes del Estado, para el armamento y abastecimiento regular del ahora "Ejército de Chile". Además la necesidad de una marina para la defensa frente a las fuerzas virreinales, permitiendo la existencia de contratistas y la participación directa en la guerra para hacer negocios, transformándose en corsarios.

\section{Comerciantes improvisados y de larga data}

$\mathrm{Al}$ alero de los nuevos gobernantes emergió un grupo que se convertiría en buena medida en el sostén económico del régimen. En la documentación aparecen casos de estos aportes privados, de los que nos enfocamos para entender la construcción de la hacienda pública. En estos identificamos la doble condición de financistas del Estado y el de comerciantes o inversionistas. Se trata de Antonio Arcos, Juan Felipe Cárdenas, Gregorio Aracena ${ }^{6}$, Diego Antonio Barros, Estanislao Lynch y Felipe Santiago del Solar. Todos ellos se destacaron en dichos roles en comparación a otros ciudadanos.

Estos nuevos negociantes, con la llegada de las tropas independentistas, continuaron con la práctica del financiamiento del Estado utilizándola como una plataforma empresarial. El rol de financistas lo fueron ejerciendo sobre la marcha, sin mucha experiencia previa en algunos casos. Sus motivaciones resultaron ser menos idealistas, incluso si se tiene en cuenta que estos estaban comprometidos con la causa de "la libertad de América" frente al rey español. Testigos de la época se refirieron a ellos como "especuladores" o "monopolistas". Pero recurrir a estos financistas internos era casi inevitable. Los gobiernos americanos no contaban con la legitimidad necesaria ni la estabilidad institucional para convencer a empresarios extranjeros de invertir en su accionar, los que sin embargo colaboraban con las autoridades, pero nunca al punto de comprometerse profundamente con un gobierno particular. Fue un hecho clave en el inicio de las actividades de dichos negociantes su llegada con las tropas independentistas, más allá de la experiencia mercantil o la conexión con el país que pudiesen haber tenido algunos previamente.

Antonio Arcos era comandante de ingenieros del Ejército de los Andes, además de encargado del plan de abastecimiento de las tropas, en un inicio al otro lado de la cordillera y luego en Chile. De esta tarea pasó a procurar el abastecimiento en calidad de proveedor privado del ejército. También fue parte de las tropas Estanislao Lynch, un bonaerense de ascendencia irlandesa que oficiaba como secretario de José de San Martín, formando parte de la oficialidad. En Chile Lynch se haría contratista del Estado como proveedor de armas.

Es notable también el caso de los civiles que llegaron en el grupo de O’Higgins y San Martín. 
Junto con los recién mencionados estaba el criollo santiaguino Diego Antonio Barros Fernández ${ }^{7}$, comerciante en Buenos Aires, dueño de imprenta, y permanente colaborador con los independentistas. Se había destacado acogiendo y dando sustento a los "patriotas" de Chile, emigrados al Río de la Plata por la vuelta al poder de las fuerzas realistas. Volvió a Chile junto con el Ejército en calidad de civil, y reinició sus actividades mercantiles. Un caso similar al de Barros es el de Gregorio Aracena, el que por su participación política sufrió la represión de los gobernadores españoles. Tras un breve exilio retornó al país a hacerse cargo de sus negocios y propiedades -traslado de mercaderías e inversiones mineras-, comprometiéndose económicamente con el bando independentista mediante varias donaciones que hizo al gobierno que aquí nos ocupa.

El caso de Juan Felipe Cárdenas es más complejo. Partidario de la independencia, pasó a ser un improvisado oficial de milicias durante el primer período revolucionario. De emigrado patriota "carrerino" pasó a ser delator de Luis Carrera, en el último intento de este de volver en secreto al país, tras el triunfo en Chacabuco. Se volvió cercano al general O'Higgins, en una sucesión de hechos que en su mayor parte desconocemos respecto de su "conversión" política, aunque Barros Arana alude a una conversación privada entre ellos, donde Cárdenas prometió su fidelidad política incondicional (Barros Arana XI, 1999: 177; Del Solar 2010: 491). Para 1818 se convirtió también en proveedor general del Ejército en las campañas en el sur del país, por los siguientes tres años. Se vería envuelto en problemas financieros, por lo que el Estado limitó sus pagos, suscitando juicios que duraron décadas. En 1826 intentó estafar al Estado utilizando una cuenta falsa de las mercaderías entregadas, lo que tampoco le resultó y provocó una pequeña crisis política mientras lideraba el país Ramón Freire (Barros Arana XV, 1999: 25-27) ${ }^{8}$.

Agregamos a este grupo del poder económico tras el gobierno de O'Higgins a Felipe Santiago del Solar, santiaguino y vástago de una familia de comerciantes, que en años previos había desarrollado sus actividades conectando los puertos de Chile y Perú (Rosenblitt 2017). Solar comenzó a trabajar de almacenero en Santiago en la tienda de su padre, Pedro del Solar Lecaros, radicándose allí y continuando su carrera mercantil. Partidario del cambio político, sufrió la relegación en Juan Fernández. Solar es el único de estos empresarios que había permanecido en Chile durante la contrarrevolución, lo que pagó con un precio alto. En palabras posteriores de su hijastro, Vicente Pérez Rosales, al comerciante Solar el comandante español Mariano Osorio le impuso "tal copia de contribuciones, de préstamos i donativos forzosos, que, a no haber sido por las relaciones mercantiles que conservaba aquella poderosa casa [comercial] en Buenos Aires, le hubiera arruinado por completo". Para mayor escarmiento de su posición política, las autoridades realistas procedieron a encarcelar a su esposa (Pérez Rosales 1886: 27). Entre los bandos "insurgentes" Felipe Santiago del Solar se mantuvo alejado del grupo carrerino, convirtiéndose en un aliado natural del general O'Higgins, una vez que este se instaló en la capital tras febrero de 1817.

Tanto Antonio Arcos como Felipe Santiago del Solar usaron la guerra para incursionar en el corso. El corsario, que podía ser el dueño del navío o su "armador", no recibía una remuneración o bonificación por parte del Estado, costeando él mismo sus actividades. El Estado le concedía el permiso, pudiendo asaltar solo los barcos de naciones enemigas en el nombre de Chile, y pagando por cada "presa" un derecho a Hacienda y a la Armada. Hacia marzo de 1819 Arcos se adjudicó una patente de corso junto con un socio, el británico William Henderson (Rector 1976: 252-253) ${ }^{9}$. Este se había desempeñado como agente personal de lord Thomas Cochrane y como representante en la adjudicación legal de las presas hechas por este (Cárdenas 1984: 73). Invertir en el corso fue un camino al que optaron algunos comerciantes del período, en vista de la debilidad de la nueva Escuadra Nacional. Solicitaban "se les liberte de los derechos de las presas que hagan a corso, premiándose por este medio el mérito i servicio de los armadores a ejemplo de lo que se ejecutó con Felipe Solar" (Letelier 1886: 398). El Senado negó la petición de Arcos referente a ser liberado de derechos, pero esto con el tiempo iba a cambiar.

Por su parte Solar armó en corso otra embarcación a fines de 1817 , contribuyendo al despegue de sus actividades comerciales y apostando a la apertura del Pacífico y al intercambio de mercaderías. Junto con su corsario Chileno, estaban sus varios navíos mercantes ${ }^{10}$. Su importancia consta en sus deudas a la aduana de Valparaíso, por las mercaderías exportadas por mar durante el año 1819. Junto con Arcos era uno de los que más 
debía dinero, dando cuenta de los volúmenes que movía. Solo en tarifas Solar debía 2.385 pesos con 3 reales y cuarto, mientras que Antonio Arcos 2.615 pesos con 3 reales y cuarto, solo superados por los comerciantes británicos o estadounidenses, consignees de casas comerciales extranjeras (Salazar 2009: 88-97) ${ }^{11}$.

La embarcación fletada por Arcos y Henderson como "armadores" era la corbeta Los Andes. Ninguno de los dos era dueño de la embarcación, aunque Henderson la había vendido previamente al Estado para que esta integrase la Armada (Cárdenas 1984: 71). Eran los inversionistas para que esta pudiese lanzarse al mar, ayudando al gobierno que había puesto otra parte. En un inicio se había hecho partícipe a los oficiales del Ejército Unido, pero casi todas las acciones fueron compradas por los socios. El Estado les entregó por mano del coronel argentino Matías Zapiola una parte, 500 pesos "en billetes (sic.)" 12 . Los socios se hacían cargo del armamento, sueldos de la tripulación, materiales, además de los víveres para todos los de abordo (incluyendo a 58 reos del gobierno) (ANH, AMM 6: f. 43).

Las ganancias de sus actividades iniciales debieron ser importantes. Arcos también invirtió en la actividad naviera, pese a la inseguridad por la continuada guerra con las fuerzas españolas, apostadas en el Callao. Sin embargo necesitaba comerciar con el Perú, ya que en agosto de 1819 se asoció con Charles Renard, militar napoleónico al servicio del ejército patriota (Berguño 2015: $329)^{13}$. Con Renard compró una embarcación menor para el trayecto entre Valparaíso y Constitución, cargando maderas que serían luego enviadas al norte (Letelier 1887: 209-210). En un registro de patentes para "navegación mercantil" del período 1818-1823, inscribió como su propiedad al menos una embarcación: el bergantín Cornelio, también llamado Aquiles (Cárdenas 1984: 55).

Posteriormente emprendió otro negocio similar con Francisco Ramón Vicuña. La idea era "fletar uno o dos buques neutrales" cargados con productos de Chile, junto con mercaderías europeas -con un valor recargado en la aduana de Valparaíso-, para ser todo transportado a Perú, saltándose al Callao. Si obtenía este permiso Arcos ofrecía al gobierno pagar una tarifa del $200 \%$ en la aduana, sobre el avalúo de los "frutos del país" que pretendía expor$\operatorname{tar}^{14}$. Arcos y Vicuña pedían seis licencias, que se le concedieron con la condición "de que presten, al arbitrio del Supremo Director, algún servicio en la espedicion libertadora [...]" (Letelier 1887: 254). El gobierno se reservaba el tipo de servicios pedido al comerciante, dependiendo del tipo de mercadería que llevase, distinguiendo claramente entre producción nacional o bienes importados y manufacturados europeos ${ }^{15}$.

Vicuña en su pedimento señaló que "Los de esta Profesion [comerciantes] deliramos en busca de algun objeto q. nos favoresca y no le encontramos; por que nuestros Calculos escollan contra la preponderancia, y ventajas del Extranjero [...]"16. Los extranjeros se imponían a los nacionales, según Vicuña, porque los respaldaba una "bandera reconocida", en una línea similar a lo que planteaba el comerciante Trucios. Llegaban fácilmente a los "puertos francos" del Perú por ser neutrales. Agreguemos que a los comerciantes españoles que mostraron lealtad política y deseos de ser chilenos no se les consideró como "extranjeros", por lo que Arcos era tenido por un comerciante "nacional" (Betancourt 2012: 125). Ante la colaboración financiera al Estado, el origen del comerciantefinancista no era relevante. Las urgencias del erario así lo requerían, y la experiencia de otros procesos de construcción estatal en Latinoamérica también lo demuestran (Tenenbaum 1985; Galmarini 2000; Contreras 2012: 41-45).

Los puertos francos eran el deseo de agricultores y comerciantes de Chile, por lo que solicitaron volver a poner en funcionamiento ese circuito mercantil por medio de permisos especiales. Era la intención "neomercantilista" también del Consulado, pues las exportaciones fomentarían las actividades productivas (Sagredo 1989: 279). El gobierno dio la autorización y comenzó a entregar los "pasavantes" correspondientes. Así el gobierno permitía la exportación al mercado peruano, admitiendo también los productos europeos hacia esos territorios enemigos. Quedaba estrictamente prohibido el comercio de armas o pertrechos bélicos (Soto 1998: 41). Convenía a todos: al gobierno, interesado en fomentar el comercio local, a los comerciantes y también a los productores. Además era lo que querían los extranjeros, principalmente británicos y estadounidenses. Las embarcaciones chilenas pagarían un impuesto de 15 pesos la tonelada embarcada, y los navíos extranjeros el doble, por lo que convenía a estos últimos iniciar sociedades junto a negociantes locales (ANH, ACG 1050, pieza 117, f. 467). 


\section{Repensando el vínculo, perfilando la red}

¿Se puede hablar de una "red" en el caso de un grupo de empresarios, no asociados todos entre sí? Eran potenciales competidores que se disputaban un espacio geográfico y económico. Es una pregunta ineludible, más allá de las preferencias políticas de todos los antes mencionados-cercanos, amigos o partidarios de Bernardo O'Higgins-. No podemos desconocer que esta última situación respondía principalmente a ciertas circunstancias, una coyuntura política especial que podría haber cambiado.

Debemos primero entender lo que se encuentra en los fundamentos de una red de personas, que tiene además íntima relación con la función de estas. Comprendemos a las redes sociales como entramados de múltiples relaciones, entre varios actores o sujetos históricos. El entramado sugiere una "estructura" amplia, más o menos permanente en el tiempo, que es más fácil de observar en los fenómenos de sociabilidad a propósito del funcionamiento de instituciones, aunque no exclusivamente en dichas realidades, sino que, por ejemplo, ha sido observable históricamente tratándose de la actividad mercantil y financiera. En este mismo sentido, entendemos "red social" no como un ente estático desde el punto de vista conceptual, sino que en realidad como una "noción" provechosa para la interpretación social y económica (Sánchez Santiró 2007; Ibarra y del Valle Pavón 2007; Alcántara, Ibarra y del Valle Pavón 2017). La existencia de la red se da porque, además de los vínculos entre los actores que la componen, este entramado social opera en un sentido específico. El mero vínculo no justificaba la existencia de un grupo, ni siquiera reviste de trascendencia a un conjunto permanente de contactos o asociaciones de diverso tipo. $\mathrm{La}$ metáfora de la red observada entre personas, instituciones o grupos - de ahí el que se utilizan elementos gráficos para mostrarlas-apunta precisamente a un mecanismo, imaginada justamente en la forma física de una "red" (como una telaraña). El mecanismo está orientado a objetivos: es una herramienta que sirve a una agenda. Las redes humanas no son un fin en sí mismo, sino que han sido un medio para otra cosa. Al identificar una "red social", podemos usarla en el contexto de una estrategia de análisis. El conjunto de relaciones y vínculos es una expresión posible de rastrear en el pasado y que en realidad está mostrando un movimiento de fondo, que es conveniente que el historiador identifique para la comprensión más profunda de un proceso histórico.

Tanto Antonio Arcos, Diego Antonio Barros, Estanislao Lynch, Felipe Santiago del Solar y Juan Felipe Cárdenas podían tener un interés en común: no estorbarse ni competir para que todos pudiesen lograr sus propios intereses económicos particulares, plenamente desarrollando sus negocios, en una suerte de modesto y tácito equilibrio. Pero esto es todavía muy débil considerando el objetivo de la supuesta red, o respecto de la naturaleza de los vínculos que por necesidad esta debía tener.

Avanzamos un poco más si consideramos que para que este pequeño equilibrio se diese el gobierno debía lograr mantenerse en pie, sin mayores estorbos o amenazas. El factor común entre ellos era ese, la vinculación con los gobernantes, además de la dependencia contractual. Si caía el gobierno sus negocios zozobraban junto con este, sin certeza del futuro, por la emergencia de otro grupo en el poder político y nuevos competidores. No tendrían preferencia ni protección gubernamental. Si la guerra iba mal todo acabaría. Por tanto, vemos aquí otro elemento: la red existe por una concertación entre los integrantes del grupo, implícita o formal.

Aparte de la función, objetivos o finalidades de las interacciones entre varios empresarios, tenemos el tipo o calidad de los vínculos. La red no puede existir sin los nexos entre quienes la componen. En la base de estas vinculaciones se encuentran situaciones específicas y de relevancia variable. Son dimensiones del poder social expresadas en claves familiares, de compadrazgo, políticas y de vinculación con el quehacer económico (Acosta 2000). Tenemos entonces efectivamente conformada a una red de comerciantes y observamos en ellos dichas claves, sobre todo la política y lo económico. El gobierno era entonces, quizás sin quererlo, el articulador de esta red.

La figura clave para la conformación de la red era el ministro de hacienda de O'Higgins, José Antonio Rodríguez Aldea, cercano a los negociantes Barros y Solar, y en particular vinculado a Antonio Arcos. Junto con este, Rosa Rodríguez, media hermana del Director Supremo, también acusada de ser asociada al proveedor Arcos, a Solar y a Diego Antonio Barros, utilizando la íntima cercanía con su hermano para influir en beneficio de dichos comerciantes. El ministro habría tenido un negocio personal con Antonio Arcos, a propósito de una contrata por venta de armamentos al Estado, lo 
mismo para el caso del otro proveedor, Estanislao Lynch. Además Rodríguez y Arcos, junto con la hermana de O'Higgins, habrían tenido una sociedad para la importación de tabacos, beneficiándose de un trato preferente facilitado por el socio ministro (Vicuña Mackenna 1931: 91). Arcos era recomendado del general San Martín, lo que consta en todos los antecedentes que manejamos respecto de su trayectoria. Creemos que el caso de Estanislao Lynch era semejante debido a su cercanía con el rioplatense, aunque no tenemos datos concretos de esta recomendación. A Barros se lo conocía como un importante civil y hombre de negocios, probablemente el más importante de ese ámbito entre los patriotas, pues había ayudado siempre a la causa. A Felipe Santiago del Solar lo unía una amistad personal con O'Higgins, manifestada a lo largo de varios años, incluso después de la marcha del gobernante al Perú tras su dimisión.

\section{Corrupciones o informalidades. La venalidad de un ministro}

Se han escrito varias razones para explicar la caída del gobierno de O'Higgins: el autoritarismo, concentración "excesiva" del poder en su persona, o medidas de orden político calificadas como abusivas ${ }^{17}$. Sus adversarios dijeron que este era "despótico", una acusación que desde el lenguaje liberal se utilizaba para deslegitimar a las monarquías. Se decía que la acción de su gobierno estaba orientada a favorecer a una camarilla de personajes, sus amigos y cercanos. Sus acciones habrían estado digitadas además, de manera oculta, por la famosa Logia Lautaro (Collier 1977: 220). Además, uno de los factores puestos en el primer plano de la caída del gobierno es la supuesta "corrupción" del ministro de Hacienda Rodríguez Aldea. Tal es el rol de este en el descrédito en que terminó el gobierno que el historiador Simon Collier aseguraba: "[...] el error más fatal de O’Higgins fue, ciertamente, su designación de José Antonio Rodríguez Aldea como Ministro de Finanzas en 1820" (Collier 1977: 220-221).

Una vez que el gobierno cayó, el 28 de enero de 1823, aparecieron las denuncias acerca de este ventiladas públicamente, involucrando al cuestionado ministro de Hacienda. En un pasquín se describía el estado de las finanzas públicas bajo Rodríguez: "apenas entró en el ministerio, se hablaba de sus negocios y de sus fondos", señalaba Bernardo de Vera y Pintado, redactor de El Interrogante y Respondente ${ }^{18}$. Acusando a Rodríguez y a otros que habrían posibilitado su ascenso al cargo de ministro de Hacienda, continuaba: "alguno de estos en los destinos que habían tenido se habían enriquecido con las grandes negociaciones, que habían hecho con los señores Arcos, Solar y Barros, protegiendo sus contrabandos, haciendo con ellos contratas ruinosas al Estado, y concediéndoles privilegios de la misma especie" (CHDI, XXXVI, 216).

Los críticos involucraban directamente a los financistas. Se acusaba al saliente ministro de deprimir las finanzas públicas mediante contratos perjudiciales para el Estado, pero que eran convenientes para los contratistas. El Tizón Republicano publicaba un recetario "para hacerse rico en pocos días". Frente a lo que este "recetario" recomendaba, cuesta no hacer la relación con lo que sabemos de algunos negociantes. Estos supuestamente hacían lo siguiente: "hará que el Estado flete uno o más buques en los que se embarcan 4 tercios [de mercaderías] de cuenta de aquel, y el resto de la suya con prevención de vender caro a aquel Gobierno, y que libre contra cajas, cuyo pago debe ser preferente a todo otro como es regular" ${ }^{\prime \prime}$. Arcos, Lynch y Solar vendían productos al gobierno, con un trato preferente en sus movimientos. Los dos primeros se abastecían con el corso. Arcos con una embarcación que era propiedad conjunta con oficiales y el gobierno, una empresa que podríamos catalogar como "mixta".

Los beneficiados no solo aportaban siendo financistas del gobierno o proveedores de servicios públicos que este debía dispensar, cuestión que los Estados republicanos en construcción necesitaban imperiosamente, como vemos con las operaciones de Arcos, sino que también ponían el dinero de manera oportuna para que sus negocios particulares no se viesen interrumpidos por ninguna razón. Respecto del vínculo del ministro con Felipe Santiago del Solar, Vera preguntaba con ironía por un soborno: "¿cómo había de salir uno ahora reconviniéndole por doce mil pesos que le diera por un pasavante para trigos? [...]" (CHDI, XXXVI, 205). Los manejos del ministro eran comentados tomando la forma de una "voz pública" o rumor, sin ser acusaciones concretas, al menos mientras O'Higgins gobernó ${ }^{20}$. Un rumor público de estos manejos era el referente a unas propiedades pertenecientes al conde de Maule, que estaban en poder de Felipe del Solar. Un pariente de este, José Antonio Rosales, evitó que estas 
fuesen confiscadas por el Estado "obsequiando al Ministro Rodríguez la casa en que habita y algunos pesillos de sobornal" 21 .

En relación con Antonio Arcos, la acusación de Vera reproducía algo que ya se reclamaba en tiempos de O'Higgins. La escocesa Mary Graham recordaba de su estancia en Valparaíso en 1822: “casi me han abrumado de detalles acerca de los nuevos reglamentos de comercio, los impuestos que van á crearse y los monopolios del ministro Rodríguez y su socio Arcos" (Graham 1900: 343). También pudo observar a "los marineros que bajaron á tierra con licencia y con dinero [...] Se les dan pagarés por veinticinco pesos, de que solo reciben cuatro en dinero; el resto se les obliga á invertirlo en los almacenes que con este fin ha establecido Arcos en el puerto"(Graham 1900: 390). Esto es confirmado por otro testigo extranjero, el militar Thomas Sutcliffe, calificando a Arcos como un "especulador" del tabaco $^{22}$. También había levantado un monopolio con la azúcar, gracias a una adición hecha por el ministro a un decreto del Senado, permitiendo al andaluz seguir obteniendo el producto, a diferencia de sus competidores:

haber cometido el atentado (ahora dos años) [1821] de entreglonar un decreto del Senado que reducía todos los derechos de introducción sobre la azúcar a dos pesos, y el [Rodríguez] puso entre renglones, $a$ más de los derechos que antes pagaban, lo que doblaba el valor de ellos, y esto se decía entonces haberse hecho solo porque no encontrase concurrencia el sujeto [Arcos] que había monopolizado todas las azúcares ${ }^{23}$.

Arcos y Solar tenían una ventaja frente a otros competidores, y no solo por su conexión con Rodríguez. Mientras el resto de los comerciantes debían hacer frente a un alza en los costos de importación, en este caso del azúcar, ellos la recibían también por la vía del corso, en tanto que sus navíos tuviesen éxito. Pero no solo se hablaba del monopolio azucarero. El comerciante de Valparaíso Carlos Sánchez informaba a un socio respecto de la voluntad de acaparamiento por parte de Arcos, también por los bienes manufacturados que llegaban desde los países industriales ${ }^{24}$. Arcos vendía todo tipo de productos en Valparaíso. El inglés John Miers repite también estas acusaciones, mostrando la manera en que se armaba el monopolio, con la ayuda (o la participación interesada) del ministro. Es posible que para el caso de Felipe Santiago del Solar, o Diego Antonio Barros, el procedimiento fuese análogo:

In order to show how these speculations were conducted, two examples shall be given. The agent before-mentioned having bought up all the tobacco in the market, a new and heavy increase of duties was immediately laid upon the importation of that article; this gave a greatly increased value to the stock on hand. On another occasion, he bought up all the sugar; upon which an additional duty of eight dollars per quintal was levied on the importation of sugar: a similar transaction took place respecting foreign spirits[licores extranjeros] (Miers 1826: 96).

El agente era Antonio Arcos que, según Miers, había adquirido poder social e influencias al casarse con la sobrina del obispo de Santiago, Isabel Petronila Arlegui Rodríguez (Miers 1826: 96). Vemos el proceder atribuido al ministro, que hacía subir el precio del azúcar, tabaco, licores y yerba mate, luego de que Arcos los comprase en gran cantidad con facilidades. Eran precisamente los productos más consumidos por la población en general, junto con el trigo. El viajero francés Gabriel Lafond de Lurcy confirmaba estas operaciones indebidas, que fueron "las causas de la fortuna de don Antonio Arcos i de la espulsion de O'Higgins" 25 . El comerciante sueco Karhl Bladh calificaba al ministro Rodríguez y a Antonio Arcos como "monopolistas del Estado", incluyendo en esto a Solar, Barros y Lynch. El precio del azúcar y la yerba subieron hasta en 50\% según Bladh. Dejaba en claro el actuar ilegítimo:

Así se dictó el nuevo reglamento de Aduanas, en el cual ciertas mercaderías corrientes, de las cuales él y el Ministro, por medio de un ex-oficial español, pero en realidad comerciante chileno, de nombre Arcos, ya habían mandado comprar una cantidad considerable, fueron gravados con un impuesto enorme en forma que ellos pasaron a ser los monopolistas de estas mercaderías [...] el arancel fijado por el Gobierno hizo imposible a los demás comerciantes competir 
sin pérdidas con estos monopolistas del Estado, y en consecuencia pocas de las mercaderías se pudieron importar (Bladh 1951: 76-77).

Después de la caída del gobierno el exministro Rodríguez estuvo en prisión, sujeto a un juicio de residencia por su gestión. Allí escribió e hizo publicar a fines de mayo de 1823 su Satisfacción Pública, en que contaba su versión de los hechos ${ }^{26}$. Rodríguez planteaba que las acusaciones que se le hacían estaban mal dirigidas, porque la situación de los "contrabandos" de los comerciantes acusados pasaban por la fiscalización de las aduanas, no por el ministerio. Hacía caer la responsabilidad a otros funcionarios públicos, estableciendo que la cartera de Hacienda no podía hacer mucho frente a situaciones que eran hipotéticas, aunque no las negaba de plano. Acusaba la injusticia de estas denuncias, pues se ensuciaba la imagen de él y la de "comerciantes bien acreditados". Respecto de Arcos aseveraba: "Don Antonio Arcos (a quien consideraba por sus conocimientos y franqueza para servir al Estado en los grandes apuros), jamás tuvo conmigo negociación alguna, [...]" (CHDI, XXXVI: 261). Afirmaba que Arcos no era su amigo ni estaba en buenos términos con él, por lo que las acusaciones a su gestión habrían sido parte de una trama de mentiras. En el fondo acusaba una persecución política:

más que gratitud, tenía yo queja contra él en lo privado, pués me vendió un fardo de azúcar, y unos cajones de vino para mi gasto, y cuando después me dio la cuenta para el pago, cargó un peso más en arroba de la azúcar y dos reales más en botella de vino del corriente en que supe había vendido a otros. También fió a dos parientes míos, bajo mi firma, dos mil pesos con plazo de seis meses, y antes de correr dos tuve que entregárselos por fuertes reconvenciones, $\mathrm{y}$ porque rebajó cien pesos en cada mil (CHDI, XXXVI: 261. Las cursivas son mías).

Si dejamos las sospechas sobre el beneficio intencionado, de todas maneras queda en evidencia que tenían varios negocios "en lo privado", por lo que el límite entre dicha dimensión y su rol público es difuso. Observamos lo que hoy conocemos como un "conflicto de interés".
Rodríguez también salía al paso de quienes lo vinculaban con el negocio de tabacos de Arcos, utilizado se supone como medio de pago por parte del Estado. Era comprado a Arcos a un precio distinto, más alto que al resto de los vendedores. Lo traía desde Virginia, Estados Unidos, no pagando derechos porque lo vendería al gobierno. El exministro recordaba: "Fui llamado una mañana ante S.E. para oír la queja de Arcos, sobre que los ministros de la Tesorería lo habían sorprendido en la compra de una partida de tabacos, pagándoselos a dos pesos menos del precio" (CHDI, XXXVI: 261). Cuando no se le pagaba lo que pedía, Arcos hacía el reclamo directamente al Director Supremo. Más allá del pago que pretendía el español queda claro que este era un proveedor importante. Si no era responsabilidad del ministro este tipo de contratas, ¿por qué O'Higgins preguntó a este por el asunto? Vemos la contradicción del ministro en su defensa y también un indicio acerca de las decisiones en el Estado. La última palabra la tenían los altos dignatarios de gobierno, limitando el funcionamiento institucional. "Por más que alegó y se empeñó en que se le abonasen los dos pesos más en quintal, no quise acceder, y menos a que le devolviese el tabaco" ${ }^{27}$, decía Rodríguez, asegurando no existir un trato preferente.

Las pistas aportadas por el mismo Rodríguez de su "verdadera" gestión son varias. Se decía que a Arcos se le habían pagado 45 pesos por el quintal de tabaco virginio, a diferencia de los otros proveedores del estanco, que habrían recibido 41 o 43 pesos. El producto debía ser comprado "del modo que estuviesen" (CHDI, XXXVI: 269), sin importar calidad. Rodríguez exponía una carta a O'Higgins donde contaba que Arcos lo había visitado enfurecido, porque le estaban pagando menos por el tabaco. Sin embargo en ella indirectamente reconocía la existencia de una influencia indebida. Omitimos el hecho de que Arcos se sintió con la confianza de ir a reclamarle:

Yo le he dicho [Rodríguez a Arcos] que escribiría a Ud. [O'Higgins] sobre el particular y que todo se allanaría; me parece que lo mejor es acabar de recibir los tabacos de una vez, y que Ud. le dé solamente recibo del peso bruto de las barricas, y dejarlo que se averigüe aquí con los ministros [de la tesorería]. El gobierno, mi amigo, no puede dejar de tener consideraciones 
con un hombre que le ha servido, y que tiene siempre prontos sus grandes fondos para hacernos suplementos y sacarnos de mil apuros ${ }^{28}$.

Confirmaba la imagen que se tenía del comerciante español (Vicuña Mackenna 1831: 112). Se ve reforzada por el testimonio de Agustín Vial, exfuncionario en el Tribunal de Cuentas y reemplazante de Rodríguez en Hacienda durante septiembre de 1821. "El clamor público me obligó a oficiar que me informaran de Valparaíso el estado en que se recibieron los tabacos", recordaba Vial ${ }^{29}$. Le informaron que "se recibieron malos [...] que los de Virginia llegaron tan averiados que se tasaron como tales para pagar derechos". Juan Beiner, otro funcionario, denunció esto a la Tesorería General, a lo que se le habría contestado -según Agustín Vial"que aunque de oficio le dio éste las gracias por su integridad y celo, le significó confidencialmente la necesidad de contemporizar con don Antonio Arcos, su vendedor, por el influjo que le merecían sus importantes servicios" (CHDI, XXXVI: 296). Los tabacos para el Estado eran de bajo valor. Arcos recibió todo el pago por ellos, pese a que Vial alegó. Lo que se pudo rescatar de la yerba tuvo que ser vendido a un cura de Quillota, que intentó venderlos:

de los virgíneos nadie ha querido una libra y fueron introducidos a la Aduana de Valparaíso tan averiados que se avaluaron como tales y ya en Buenos Aires se había rescindido su venta hecha a siete pesos por el comprador que no los quiso después por cinco; sin embargo, se pagaron por el Estado dentro de la misma Aduana por 43 [pesos] (CHDI, XXXVI: 296).

Por la fuerza de la necesidad económica que el gobierno tenía -y que lo podía volver dependiente con cualquier otro negociante con recursos monetarios y pericia económica al servicio del accionar estatal-es que debemos entender que la noción de "corrupción" tal como la entendemos hoy no puede ser aplicada al contexto del gobierno de O'Higgins, como tampoco al fenómeno histórico que hacemos aquí referencia, de la relación entre negocios privados y acción del gobierno, marcado por relaciones familiares, de compadrazgo y clientelismos que caracterizó a las últimas décadas del período colonial y las primeras de vida independiente (Pietschmann
1998: 46-48; Galmarini 2000; Cáceres 2004; Mazzeo 2012; del Valle Pavón 2012). Actualmente existen canales regulares, legalizados e institucionalizados, mediante estos, los privados hacen aportes al Estado, y de hecho la reforma e implementación de estos canales ha suscitado la polémica pública en Chile durante los últimos años. Pero sí podemos apreciar, durante las primeras décadas del siglo XIX, un conjunto de situaciones entendidas en esos mismos años como irregulares, las que eventualmente podían servir para armar a los adversarios políticos, y que por tanto debían ser ocultadas del conocimiento general. Podemos verlo en varias cartas enviadas al Perú en donde Rodríguez informaba a O'Higgins del acontecer chileno. Muchas de estas estaban escritas de una forma en que no pudiese ser descifrado todo su contenido, incluyendo claves numéricas en el lugar de palabras o frases. En una misiva firmada el 7 de septiembre de 1823 le contaba:

\subsection{7 [Arcos] me ha cobrado lo dado} y le he devuelto un pagaré que me había cedido de 51.57.62.9.13.11.12 [doce mil], después que yo había gastado más de siete: no sé cómo esto no me ha hecho perder el juicio, pues llegó a volarme la cabeza. Estuve dos noches sin poder tomar sueño con una sofocación que dio cuidado ${ }^{30}$.

Llama la atención que tanto "Arcos" como "doce mil" los haya escrito en clave. ¿No quería que se conocieran esas palabras, y por esta razón el sentido completo del mensaje? Otra pregunta ante el párrafo recién citado es si esos 12.000 pesos era, precisamente, la suma que se había pagado al ministro por un "pasavante". Se acusaba que esta práctica la había hecho el comerciante Solar, pero también se nombraba a Diego Antonio Barros. ¿O tal vez esos pesos se debían a otro favor?

\section{Conclusiones}

Claramente no podemos saber quién decía la verdad, como tampoco nos interesa juzgar al antiguo ministro desde el siglo XXI. Este siempre afirmó que era su preocupación la de tomar las medidas necesarias con el fin de "no dar lugar al agiotaje" (CHDI, XXXVI: 264). Son versiones que tienen que ser consideradas a la hora de evaluar el manejo de la hacienda pública de ese período. Quizás más importante aún, dichos antecedentes muestran otra 
cara del gobierno de O'Higgins. Ayudan a entender que la empresa de la Independencia nacional, y su extensión a tierras peruanas, significó de paso el negocio de unos pocos individuos, que se valieron de su creciente poder económico para influir en aquellos que gobernaban, adecuando los objetivos de largo plazo del gobierno a sus propios intereses particulares. Algo fácil si consideramos que el Ejecutivo actuaba de manera discrecional, pasando a llevar los otros poderes del Estado, reflejando una superioridad derivada de su raíz monárquica (Chambers 2015: 113). Esto pone en entredicho el ideario liberal, mostrando que el proceso de su aplicación fue problemático. Entremedio de todo esto se consolidó la Independencia del territorio de Chile, y progresó lentamente la construcción de un Estado.

Identificamos en su accionar a un grupo pequeño, que influyó claramente en el proceso de construcción estatal. La efectividad de lo que denominamos "red de poder" fue posible por dicho contexto particular. Los aportes de estos al Estado no fueron determinantes en un sentido global, como para consolidar la Independencia chilena. Pero sí condicionaron el proceso. La suerte del nuevo gobierno no habría sido la misma sin el aporte de estos. Su influencia en el gobierno es indudable, y sus intereses modificaron el accionar del gobierno, orientando su política en materias como la legislación comercial, el control en las aduanas, los intercambios con Perú, su presencia marítima, el poder del Tribunal del Consulado, entre otras. Las operaciones orquestadas por Arcos, Barros o Solar, muchas veces comprometieron la imagen de altos funcionarios públicos. Como el caso del ministro José Antonio Rodríguez, que dio al gobierno del prócer la imagen de un período de corrupción y negociados ilegítimos. Fuera de la difícil comprobación de los hechos, las consecuencias visibles de estas influencias fueron discutidas, publicadas y usadas en aquella contingencia política. El enriquecimiento de Antonio Arcos lo muestra, aunque sabemos que también se acusó a otros comerciantes que financiaron al naciente Estado.

En esa etapa crucial se dio un quiebre definitivo con los que habían manejado el comercio a gran escala. Españoles junto a criollos de la clase dominante habían dominado el comercio chileno, fruto de sus relaciones con otros territorios. El quiebre con España y sobre todo con Perú, y el desplazamiento de estos comerciantes locales, dejó el espacio vacante. Se crearon nuevos nichos de emprendimiento, aprovechados por gente como Arcos y Lynch, o continuados por Solar. Se requería a particulares que apoyaran al nuevo Estado, tomando relevancia también el corso, que si bien no era nuevo en esos años experimenta un auge inédito. Se dieron las condiciones para un enriquecimiento rápido, comparado con los negocios en décadas anteriores. Los estudios pertinentes a estos años se han concentrado en la política contingente, o en aspectos militares, institucionales, o normativos del aparataje estatal. Todavía más, deben ser sacados de la sombra los intereses particulares, que configuraron grupos de presión e influyeron en todos esos otros procesos estudiados ya por la historiografía.

\section{Referencias Citadas}

Academia Chilena de la Historia

1968 Archivo de don Bernardo O'Higgins, Tomo XXVI. Editorial Universidad Católica, Santiago.

Acosta, A.

2000 "Las redes sociales, el poder y sus fundamentos". Anuario IEHS 15: 153-171.

Alcántara, A., Ibarra, A., y del Valle Pavón, G.

2017 Introducción. En Antonio Ibarra y Guillermina del Valle Pavón (Coords.). Redes, corporaciones comerciales y mercados hispanoamericanos en la economía global, siglos XVII-XIX. Instituto Mora, CONACYT, México D.F.: 7-26.

Barros Arana, D. 1999 [1897] Historia General de Chile, Tomo XV. Editorial Universitaria, DIBAM, Santiago.

Barros Arana, D.

1999 [1890] Historia General de Chile, Tomo XI. Editorial Universitaria, DIBAM, Santiago.
Berguño Hurtado, F.

2015 Los Soldados de Napoleón en la Independencia de Chile (1817-1830). RIL, Santiago.

Betancourt Castillo, F.

2012 "Los comerciantes españoles y el proceso de Independencia en Chile. Estrategias y desventuras en una época de cambios". Tiempo Histórico 4: 121-138.

Biblioteca Nacional

1953 Colección de Historiadores y de Documentos relativos a la Independencia de Chile (CHDI), Tomo XXXVI. Imprenta Cultura, Santiago de Chile.

Bladh, C.

1951 La República de Chile 1821-1828. Sociedad Chilena de Historia y Geografía (Colección de viajeros relativa a Chile), Imprenta Universitaria, Santiago.

Cáceres Muñoz, J.

2004 "Los comerciantes de Colchagua: redes de familia, política y clientela, 1750-1830". En Estudios Coloniales 
III, Julio Retamal Ávila (coord.), Universidad Andrés Bello, Santiago.

Cárdenas, J.

1856 Al Soberano Congreso de 1856. Imprenta de la Sociedad, Santiago.

Cárdenas G., M.

1984 Corso y guerra marítima en Chile, 1797-1824. Tesis de Magíster en Historia, Universidad de Chile, Santiago.

Chambers, $\mathrm{S}$.

2015 Families in War and Peace. Chile from Colony to Nation. Duke University Press, Durham.

Collier, S.

1977 Ideas y política de la Independencia chilena 1808-1833.

Ed. Andrés Bello, Santiago.

Contreras C., C.

2012 La economía pública en el Perú después del guano y del salitre. IEP, Lima.

Ibarra, A. y Del Valle Pavón, G.

2007 "Redes sociales e instituciones: nuevas miradas sobre viejas incógnitas". Historia Mexicana LVI, 3: 717-723.

Galmarini, $\mathrm{H}$.

2000 Los negocios del poder. Reforma y crisis del Estado 1776-1826. Ediciones Corregidor, Buenos Aires.

Garreaud, J.

1981 A dependant country: Chile, 1817-1861. Ph D Dissertation, University of California, San Diego.

Graham, M.

1900 [1824] Diario de su residencia en Chile (1822) y de su viaje al Brasil (1823). Biblioteca Ayacucho, Editorial América, Madrid.

Guerrero Lira, C.

2002 La contrarrevolución de la independencia en Chile. DIBAM, Santiago.

Jaksic, I. y Serrano, S.

2010 "El gobierno y las libertades. La ruta del liberalismo chileno en el siglo XIX”. Estudios Públicos 118: 69-105.

Lafond de Lurcy, G.

1911 [1853] Viaje a Chile (trad. de la edición francesa de 1853 por Federico Gana), Santiago.

Letelier, V. (comp.)

1886 Sesiones de los Cuerpos Lejislativos de la república de Chile 1811 a 1845. Tomo II. Imprenta Cervantes, Santiago.

Letelier, V. (comp.)

1887 Sesiones de los Cuerpos Lejislativos de la república de Chile 1811 a 1845. Tomo III. Imprenta Cervantes, Santiago.

Mazzeo de Vivó, C.

2012 Gremios Mercantiles en las guerras de independencia. Perú y México en la transición de la colonia a la República, 1740-1840. IEP, Banco Central de Reserva del Perú, Lima.

Méndez Beltrán, L.

2004 La exportación minera en Chile 1800-1840. Editorial Universitaria, Santiago.

Miers, J.

1826 Travels in Chile and La Plata, Vol. II. Printed for Baldwin, Cradock, and Joy, Londres.

Ortega M., L.

2018 [2003] Chile en ruta al capitalismo. Cambio, euforia y depresión. LOM, Santiago.

Pietschmann, $\mathrm{H}$.

1998 "Corrupción en las Indias Españolas: revisión de un debate en la historiografía sobre Hispanoamérica colonial". En Manuel González Jiménez, Horst Pietschmann, Francisco Comín y Joseph Pérez. Instituciones y Corrupción en la
Historia. Instituto de Historia Simancas, Universidad de Valladolid, Valladolid: 31-52.

Pérez Rosales, V.

1886 Recuerdos del pasado 1814-1860. Imprenta Gutenberg, Santiago.

Rector, J.

1976 Merchants, trade, and commercial policy in Chile: 1810-1840. Indiana University Press, Indiana.

Rosenblitt B., J.

2017 "Inicios de la expansión del comercio chileno en el Pacífico sudamericano. El paso de Pedro del Solar por la región Tacna-Arica, 1784-1813". En Empresas y empresarios en la historia de Chile: 1810-1930, editado por M. Llorca Jaña y D. Barría (eds.), Editorial Universitaria, Santiago.

Sagredo Baeza, R.

1989 "Pragmatismo proteccionista en los orígenes de la República”. Historia 24: 267-286.

Salazar V., G.

2009 Mercaderes, empresarios y capitalistas. Chile, siglo $X I X$. Sudamericana, Santiago.

Sánchez Santiró, E.

2007 "Las incertidumbres del cambio: redes sociales y mercantiles de los hacendados-comerciantes azucareros del centro de México (1800-1834)". Historia Mexicana LVI, 3: 919-968.

Solar Guajardo, F.

2005 La Logia Lautaro: el poder de la Masonería durante la Dictadura de O'Higgins 1817-1822. Tesis Licenciatura en Historia, Pontificia Universidad Católica de Chile, Santiago.

Solar Guajardo, F.

2010 “José Miguel Carrera. Redes masónicas y sociedades secretas durante las guerras de independencia en América del Sur". En La Masonería Española. Represión y exilios I, coordinado por J. A. Ferrer. Gobierno de Aragón, Departamento de Cultura, Zaragoza, pp. 475-496.

Soto Acuña, E.

1998 El costo y la organización de la Expedición Libertadora del Perú 1818-1820. Tesis de magíster en Historia, Universidad de Chile, Santiago.

Sutcliffe, T.

1841 Sixteen years in Chile and Peru, from 1822 to 1839. Fisher Publisher, Londres.

Tenenbaum, B.

1985 México en la época de los agiotistas, 1821-1857. México, Fondo de Cultura Económica.

Vicuña Mackenna, B.

1931 [1861] "Mi defensa ante el jurado de imprenta que tuvo lugar en Valparaíso el 24 de Junio de 1861". Revista Chilena de Historia y Geografía 74: 30-136.

\section{Archivos y Fuentes Documentales}

Archivo General de Indias (AGI), Audiencia de Chile (Chile), Legajo 544.

Archivo Nacional Histórico de Chile (ANH), Archivo Benjamín Vicuña Mackenna (AVM), volumen 87.

Archivo Nacional Histórico de Chile (ANH), Archivo de la Capitanía General (ACG), volumen 1050, pieza No 117.

Archivo Nacional Histórico de Chile (ANH), Archivo de la Capitanía General (ACG), volumen 1054. 
Archivo Nacional Histórico de Chile (ANH), Archivo Notarial de Santiago (ANS), volumen 53.

Archivo Nacional Histórico de Chile (ANH), Archivo del Ministerio de Marina (AMM), volumen 6.
Archivo Nacional Histórico de Chile (ANH), Fondo Varios (FV), volumen 1044.

Archivo Histórico del Senado (AHS), volumen 262.

\section{Notas}

1 Este estudio de desarrolló en el marco de un convenio como Investigador Asociado del Centro de Estudios Históricos de la Universidad Bernardo O'Higgins.

2 Las licencias se extendieron hasta noviembre de 1824 (ANH, ACG 1054, pieza 1, ff. 1-138).

3 Muchos comerciantes estuvieron alejados del gobierno porque en conjunto defendían políticas económicas distintas a las impulsadas por el nuevo gobierno. La enemistad del Consulado con O'Higgins está explicada en Rector 1976: 117-119.

4 Las comunicaciones del Consulado con el Senado muestran estas permanentes quejas al Director Supremo, acerca de la situación de los comerciantes del país (AHS, 262, ff. 26-51v. La larga carta que mencionamos: José de Trucios a Bernardo O'Higgins, Santiago, 21 de mayo de 1819 (AHS, 262, ff. 40-44).

5 La zona central de Chile como un mercado de tránsito, en particular Valparaíso, es una de las ideas centrales del trabajo Garreaud. Esto ha sido suscrito por el historiador Gabriel Salazar.

6 Gregorio Aracena, comerciante de la zona de La Serena y gran exportador de minerales (Méndez 2004:190-192).

7 Padre del importante historiador de fines del siglo XIX Diego Barros Arana.

8 La versión del propio Cárdenas: (Cárdenas 1856).

9 Henderson fue uno de los 40 principales mercaderes, según los registros de aduanas en el período 1818-1828. En un catastro realizado por el gobierno: "Lista de los comerciantes ingleses residentes en Santiago y Valparaíso", Santiago, 14 de octubre de 1819 (Letelier 1887: 306).

10 Estas eran la Mercurio Americano, Cazadora, Concordia, Perla, Jeresana, Gaditana, Ceres y Pallas.

11 "Relación de dudas pendientes por plazos cumplidos correspondientes a la cuenta de la Aduana del puerto de Valparaiso, que corre al cargo de su Administrador Don Manuel Gormaz". Sesión extraordinaria del Senado, del 16 de diciembre de 1819 (Letelier 1887: 440-450).

12 "Declaracion Dn. Antonio Arcos", Santiago, 10 de abril de 1819 (ANH, ANS 53, f. 58). Los billetes fueron entregados a Arcos por el coronel Matías Zapiola. Respecto de la pertenencia de Zapiola a la Logia Lautaro (Del Solar 2005: 104).

13 Charles Prospere Renard llegó a Chile junto con Jorge Beauchef y Bellina Skupieski, poco después de la batalla de Chacabuco. Sirvió como teniente del regimiento de Cazadores a caballo del ejército chileno, peleando en Maipú.

14 Antonio Arcos al Director Supremo del Estado, 7 de octubre de 1819 (ANH, ACG 1050, pieza 117, f. 463; Letelier 1887: 253-254).

15 Sobre la "Expedición Libertadora al Perú", solo mencionaremos que tanto Antonio Arcos como Felipe Santiago del Solar presentaron propuestas para ser los empresarios privados de la misma, ganando finalmente la de Solar en compañía con los trasandinos Nicolás Rodríguez Peña y Juan José de Sarratea.

16 Francisco Ramón Vicuña al ministro Joaquín de Echeverría (ANH., ACG 1050, pieza 117, f. 464).

17 El gobierno de O'Higgins se habría caracterizado por "políticas de corte liberal [...] y medidas dictatoriales que generaron suficiente oposición como para forzar su abdicación en 1823" (Jaksic y Serrano 2010: 73).

18 "Contestación al Interrogante", firma "El Respondente" (Bernardo de Vera y Pintado). El Interrogante y Respondente, $\mathrm{N}^{\circ} 1$, jueves 13 de marzo de 1823 (CHDI, XXXVI: 216).

19 "Reglamento util y provechoso para hacerse rico en pocos dias cuya virtud esta en el mismo, saber donde se usa y en que...etc.". Tizón Republicano, $\mathrm{N}^{\circ}$ 2, Santiago, lunes 3 de marzo de 1823 (CHDI, XXXVI, 205).

20 John Miers recuerda de esto: "It was suspected that the sister of O'Higgins [Rosa O'Higgins] participated in the speculations and ilegal gains of the minister [Rodríguez Aldea] and his agent [Antonio Arcos], but no one ever ventured to impute any connivance in the transactions to the director; and had any such connivance existed, it would no doubt haver been brought to light after his abdication" (Miers 1826: 96).

21 "Señor Editor", en El Interrogante y Respondente, $\mathrm{N}^{\circ} 2$. Santiago, jueves 27 de marzo de 1823 (Miers 1826: 224-225).

22 "but those of the Chilian squadron, whose daring prowess had freed the Pacific, and enabled the Liberating army to enter and invade Peru, were not only excluded from being participators of the Peruvian bounty, but had the mortification of being denied the prize-money that was due to them; and on their return to port, were paid their arreas in notes issued by a Spanish speculator, or in tobacco, by which they had to suffera considerable discount, or sell the latter at an enormous loss [...]" (Sutcliffe 1841: 63).

23 "Contestación al Interrogante". El Interrogante y Respondente, $\mathrm{N}^{\circ} 1$, jueves 13 de marzo de 1823 (CHDI, XXXVI, 217).

24 Carlos Sánchez a Paulino Campbell. Valparaíso, 29 de marzo de 1822. (ANH, FV 1044, f. 4).

25 (Lafond de Lurcy 1911: 73-74): "Nada tenia de estraño, entonces, que se dictasen leyes i decretos que beneficiaban algunos intereses particulares. Se acaparaba una mercadería, i, sin buscar un pretesto, se la gravaba con un derecho exorbitante. Tales fueron las causas de la fortuna de don Antonio Arcos i de la espulsion de O'Higgins".

26 Nos referimos al documento Satisfaccion Publica del Ciudadano Jose A. Rodriguez ex Ministro de Hacienda y de Guerra, firmado el 28 de mayo de 1823. Rodríguez Aldea, "Satisfaccion publica del Ciudadano Jose A. Rodriguez ex 
Ministro de Hacienda y Guerra", Santiago, 28 de mayo de 1823 (CHDI, XXXVI, 235-285).

27 Según los datos se puede decir que este cargamento de tabaco era enorme, pagando solo en derechos 50.000 pesos. Los otros que vendían tabaco al Estado, y que por tanto competían con Arcos, eran dos comerciantes que eran sus agentes (y al mismo tiempo con negocios propios), Pedro García de la Huerta y Josué Waddington. Además, Juan José Mira, Joaquín Trucios, Pedro Palazuelos, José Ignacio Zamora, Nicolás Rodríguez Peña, y Olof Liljevalch (CHDI, XXXVI: 261).

28 (CHDI, XXXVI: 269) José Antonio Rodríguez Aldea a Bernardo O’Higgins. Sin fecha. Las cursivas son mías.
29 Agustín Vial Santelices, Manifiesto de la Conducta Publica de Agustin Vial, calumniada por la Satisfaccion Publica del Ciudadano Jose Antonio Rodriguez. Santiago, 1823 (CHDI, XXXVI: 295-296). Las cursivas son mías.

30 José Antonio Rodríguez Aldea a Bernardo O'Higgins. Santiago, 7 de septiembre de 1823 (ANH, AVM 87, f. 166). Esta carta también fue publicada en CHDI, XXXVI: $317-$ 319 , donde aparece la clave de los números que aparecen en esta correspondencia. Entre las claves descifradas y publicadas aparecen algunas referentes a nombres de personas. Como es de esperar, los de la hermana de O'Higgins, así como los de Solar, Barros y Lynch. En una carta también se mencionaba al serenense Gregorio Aracena. 
